\title{
New educational formats for professional development: Accommodating the invisible learners
}

Reference: Littlejohn, A., Jaldemark, J., Vrieling-Teunter, E., \& Nijland, F. (2019). Networked Professional Learning: An Introduction. In Networked Professional Learning (pp. 1-11). Springer, Cham.

https://link.springer.com/book/10.1007/978-3-030-18030-0

Christian Dalsgaard, Centre for Teaching Development and Digital Media, Aarhus University, cdalsgaard@tdm.au.dk

Tom Gislev, Centre for Teaching Development and Digital Media, Aarhus University, tgislev@tdm.au.dk

\begin{abstract}
The motivation of this chapter originates in an interest in the so-called dropouts, non-completing or disengaged participants of Massive Open Online Courses (MOOCs). In this chapter called invisible learners. Invisible learners are defined as the non-active and disengaged participants of MOOCs, who do not participate in and complete the course activities and possibly also drop out of the course. The objective of the chapter is to study how to characterise different learner groups in MOOCs, and to discuss, which educational formats can accommodate invisible learners in professional development. The chapter is based on an empirical study of an open online course designed specifically for different types of learner engagement by allowing for different levels of participation. The study is primarily based on 11 interviews and a questionnaire answered by 51 participants. The analysis identifies five different levels of participation, named students (enrolled), attendees, members, observers and visitors. The chapter concludes that activities and assignments of students and attendees in a MOOC can provide a key centre for networked learning activities of invisible students that use these activities as part of or as an extension of their own professional practices.
\end{abstract}

Keywords: invisible learners, MOOCs, networked learning, open education, professional development

\section{Introduction}

The motivation of this chapter originates in an interest in the so-called dropouts, non-completing or disengaged participants of Massive Open Online Courses (MOOCs). In this chapter called invisible learners. Invisible learners are defined as the non-active and disengaged participants of MOOCs, who do not participate in and complete the course activities and possibly also drop out of the course. They leave no or few traces of activity for the course providers to register. They are often termed inactive or disengaged, and they do not do the assignments, quizzes, and tests in the MOOC that they have registered for.

The massive part of most MOOCs are actually the participants that do not complete the MOOC. Only a small minority (of about $10 \%$ ) complete the course as intended by the MOOC providers (Jordan, 2014). Thus, one could argue that if the aim of MOOCs is the M, then focus should be turned towards the non-completing group. Whereas low completion rate can be viewed as a major shortcoming of MOOCs, this paper wishes to focus on the non-completing. Not with the intention of necessarily aiming for increasing the completion rates, but rather to study the motives and needs from the noncompleting participants - and to explore educational formats that accommodates this group. 
This chapter is based on an empirical study of an open online course designed specifically for different types of learner engagement by allowing for different levels of participation. The study is primarily based on 11 interviews and a questionnaire answered by 51 participants. Based on the findings of the study, the paper will discuss and question the MOOC format as a relevant educational format for the 'massive' group of non-completing participants. The main critique of the MOOC format in relation to this target group is the $\mathrm{C}$, the course format. The findings from the current empirical study show that some of the participants were from the outset not interested in completing a course or doing assignments.

As Littlejohn and Hood (2018) argue, there is often a conception that completing is the best and most valuable way of participating in a course. However, MOOCs "have the potential to legitimise learning behaviour that in traditional contexts would be characterised as deviant, nonlearning, associated with failure" (Littlejohn \& Hood, 2018, p. 50). A number of previous studies have examined how learners participate in different ways in MOOCs (Littlejohn \& Hood, 2018). Milligan, Margaryan, and Littlejohn (2013) distinguish between three types of learner engagement; active participation, passive participation, and lurking. Further, their study identified that different factors such as confidence, prior experience and motivation influenced participants' engagement. Clow (2013) introduced the metaphor of 'funnel of participation' to describe their findings of a steep decline in student participation during the run of a course. They conclude that unequal participation is characteristic of MOOC learners. Finally, a widely used typology has been developed by Kizilcec, Piech, and Schneider (2013) in a study of subpopulations of MOOC participants. Along with the other study, this study shows that completing a course is not be the only way of learning from a MOOC. The study identifies four prototypical types of learner engagement in MOOCs: learners completing, auditing, disengaging and sampling. A key finding in Kizilcec, Piech, and Schneider (2013) is that within all types of learner engagement there were satisfied participants. For example the auditing participants generally expressed a high degree of satisfaction, although none of them completed the course.

\section{Invisible learners in professional development}

A hypothesis behind the current study is that the ways in which invisible learners utilise MOOCs is of particular relevance to professional development. A target group aiming at professional development has different motives and objectives than students enrolled at a university. Thus, it is relevant to study activities and forms of participation in MOOCs for such a group. As Ho et al. (2015) also argue, it might be fruitful for 'disengaged' users to participate in MOOCs without completing:

"If we wished only to increase overall certification rates, one solution is simple: restrict access. Online browsers, online explorers, and teachers-as learners would not benefit from such a policy. And MOOCs would lose their first two letters and much of their claim to innovation, instead becoming familiar, smaller, online courses" (Ho et al., 2015, p. 33)

The point made by Ho et al. (2015) is that a strict focus on participants who complete a course, might overlook a group of participants that utilise the course content and activities in different ways, and possibly in ways not intended by the course providers. Ho et al. (2015) indicate that the noncompleting will also benefit from MOOCs. This is supported by the study of MOOC participants in Kizilcec, Piech, and Schneider (2013) and Littlejohn, and Hood (2018). These results suggest that there are educative potentials within other levels of participation than completing MOOCs. In the study presented in this chapter the focus is on potentials of invisible learners related specifically to professional development. 


\section{Research questions}

Based on the discussion above, the chapter explores the following research questions:

1. How can different learner groups in MOOCs be characterised?

2. What are the activities, needs and learning outcomes of invisible learners?

3. Which educational formats can accommodate invisible learners in professional development?

Based on an empirical study of user activities in MOOCs, the chapter will investigate activities of different learner groups. Further, the study will more specifically examine activities, needs and learning outcomes of invisible learners. This finally leads to a discussion of how new kinds of educational formats might support professional development.

\section{The (M)OOC design of the study}

The MOOC in the study was designed specifically to be able to study the research question. This also means that the findings of the study cannot be generalised to other MOOCs. The objective of the study is to identify emerging patterns of participation.

In order to study the research questions, a MOOC was designed to accommodate different levels of participation, inspired by Kizilcec, Piech, and Schneider (2013), and also to invite participants seeking professional development. This meant that the different participants could choose to participate in a number of activities; write blog posts, comment on blog, read literature, watch teacher videos, work on assignments, and read blog posts. None of the activities were prerequisites for participating in the other activities. The MOOC was designed as part of a course in a master's programme in ICT-based Educational Design at Aarhus University. The course, called "Digital Learning Contexts", was organised so that the first six weeks of the course was run as a MOOC, open for anybody who were interested in the subject matter. It was mandatory for the students enrolled in the master's programme, to participate in all activities and to hand in all the assignments because it was part of an ECTS course. Besides being part of the course, the MOOC was offered as further education targeted at educational professionals in Denmark, thus aiming at professional development. There were 25 enrolled students in the master's programme, and there were 165 registered external participants. Due to the small number of external participants, the designed course was in practice not a MOOC, but rather an OOC. However, the massiveness of participants is not key to the objectives of the current study. Rather, the most important thing for the designed course is the openness and opportunities to participate on different levels.

The (M)OOC was designed as an aggregation of different digital tools: All activities were handed in as blog posts in a Wordpress environment, Google Docs was used for group collaboration, there was a Facebook group for discussions, Youtube live was used to stream supervision sessions and record them for later viewing and Twitter was used for communication with outside interest groups.

\section{Methodology}

The research design for the study is a mixed methods approach combining qualitative and quantitative methods (Tashakkori \& Teddlie, 2010). The study is first and foremost a qualitative study aiming at in-depth analysis of different levels of participation. The studies of this paper consist of a survey answered by 51 MOOC participants, and 11 interviews with selected participants.

A survey to all the participants of the open online course was performed after completion of the course. The objective of the survey was to gather quantitative data related to the first research 
question: How do learners participate in different ways in open online courses? The survey was intended to provide a broad overview of which activities the learners had participated in, how much they had participated, and what they had achieved from the different activities. This study is inspired by Kizilcec, Piech, and Schneider (2013), but to supplement their study, the current study was not based on identifying student completion, dropout or disengagement, but rather on mapping what activities the students participated in.

As mentioned above, the MOOC was designed to allow for a number of activities: write blog posts, comment on blog, read literature, watch teacher videos, work on assignments, and read blog posts. These activities formed the basis of the survey, that examined the students' participation in each activity and the learning outcome of each activity. For the study in this paper, the key question in the survey is shown in Table 3.1. The participants were asked about their level of participation in the activities of 1) online tutoring, 2) reading literature, 3) watch teacher videos, 4) work on assignments, 5) write blog posts, 6) read blog posts, and 7) comment on blog.

Table 3.1. Questions in the survey

The questionnaire also contained background questions on age, gender, educational background, residence, and job status.

To establish a terminology to discuss the participants' level of engagement in the different activities, the study reflects on the nature of the different activities and what here is chosen to call the visibility of the activity. As mentioned above, the study includes the following activities of the course:

- Write blog posts (visible)

- Comment on blog (visible)

- Read literature (invisible)

- Watch teacher videos (invisible)

- Work on assignments (invisible)

- Read blog posts (invisible)

Even though the focus was on experiments and discourse, reading was still a central part of the course design. There was a basic course syllabus containing academic literature, that the participants were encouraged to read. Furthermore, the participants were also encouraged to read each other's blog posts and the comment threads that branched out from these blog posts. In this study reading was regarded as an invisible activity, because there was no reliable way to detect whether the participants had read the abovementioned texts. Albeit indications on the participants' reading activities can be obtained by looking at their blog posts and comments, it only is circumstantial evidence at best, and don't give a clear picture of the participants' level of engagement in terms of reading, hence reading is regarded as an invisible activity. Also, work on assignments is invisible, because it involves making analyses, observations and experiments in practice. Blog posts are the final outcomes of the assignments, but not all participants wrote these when working on assignments.

The objective of the qualitative study was to go further into depth with the first research question 'How can different learner groups in MOOCs be characterised?', and more specifically to study in detail the second research question: 'What are the activities, needs and learning outcomes of invisible learners?' The qualitative study consisted of interviews with MOOC participants. For the interviews the following interview guide was developed and used: 
Table 3.2 Interview guide

11 interviews were completed with participants of the course. The 11 interviewees were chosen in order to represent a variation in course participants. Thus, the aim was to pick interviewees from the different categories of participation identified from the survey. Based on activities on the blog (both posts and comments), the Facebook group and in Google Drive, students with different levels of participation were chosen and contacted by email.

\section{Participants}

51 of the 165 registered participants filled in the questionnaire. Their average age is 46 years. $66,7 \%$ are female $(\mathrm{n}=34)$ and $33,3 \%$ are male $(\mathrm{n}=17)$. The majority of the participants have a former degree; $33,3 \%$ have a professional or university bachelor $(n=17), 37,3 \%(n=19)$ have a master's degree and $25,5 \%(n=13)$ a different higher education degree. The majority of $82,4 \%(n=42)$ have a full-time job. To a large extent, the majority of the participants would be the typical target group for continuing education.

\section{Different levels of participation}

51 participants answered the questionnaire. Of the 51, 39 had started the course, whereas the remaining 12 did not do any course activities. Thus, they did not answer the questions in Table 3.1 concerning course activities. The results from the 39 responses are shown in Table 3.3 below. The table shows the levels of participation within each of the seven activities and a total level of participation from each of the participants.

40 out of the 51 respondents ended up starting the course, whereas the remaining 11 never started the course and did not participate. The latter 11 are not included in the results presented below, because they did not answer questions regarding their course activities. Table 3.3 shows each of the 40 participants' answers to the question 'How much have you participated in the following activities in the course?' The table shows which activities each participant has engaged in and also the level of engagement within each activity (points from 0-4). The participants are sorted by the total level of engagement, which is calculated by adding up the points for participation in each activity. The table shows a large variation in student activities and engagement and no obvious patterns of participation.

Table 3.3 Participation sorted by total level of participation

17 participants were engaged in visible activities, whereas 23 participants were only engaged in activities invisible to the teacher and the other participants. To sort the participants by degree of visibility, each participant's percentage of 'visible' and 'invisible' activities were calculated. Looking only at the 23 invisible participants, Table 3.4 shows that they have primarily watched videos, read the course literature and read the blog posts written by the visible participants. The have generally been less active than the visible participants.

Table 3.4 Participation sorted by visible/invisible

What is relevant, however, is also to look into the experienced learning outcome of the participants. A weighted average level of learning outcome was calculated for each participant based on the answers to the question 'To what extent have you learned from participation in the following activities in the course?'. The weighted average level of learning outcome only includes the activities that the participants were active in. In Table 3.5 the participants are sorted by their weighted average learning 
outcome. Although in general, the visible participants have experienced the highest learning outcome, several of the invisible participants have experienced a relatively high learning outcome, in spite of their limited participation.

Table 3.5 Participation sorted by level of learning outcome

The conclusion of the survey is that the participants have participated in the course in many different ways. They have participated in different activities, and their level of participation within the activities also varies. Within the studied sample, there is a tendency that the participants that have engaged in many of the course activities are also the ones that are most active within each of the activities. However, it should be noted that there are also examples of participants who have a relatively high level of activity within a few of the activities. For example, students number 15, 21, and 28 are relatively active within watching videos, reading blog posts - and also reading course literature (student number 7 and 15). Based on the survey data, it is difficult to divide the participants into specific groups.

However, it is possible to identify some overall patterns of participation, also with inspiration from Kizilcec, Piech, and Schneider (2013). As an answer to the first research question, participants can be identified as:

- Students (enrolled)

- Attendees

- Members

- Observers

- Visitors

Students are the enrolled students (in the ECTS course) that participate in all course activities. Attendees are external (M)OOC participants who act very similar to the enrolled students; they do all or most of the course activities and complete the course. Members are participants who may do a few of the assignments and also comment on some blog posts, but they do not complete all course activities. Observers are participants who do not leave any visible signs of activity, but only browse course literature, blog posts and videos. Finally, visitors are external viewers who have not registered for the course and only browse selected course materials.

This categorisation of participants has been used as a basis for selecting people for interviews. The aim of the participant interviews has been to further understand how they have participated in different ways, and to understand their learning outcomes and needs for learning. Of the 14 interviews, three were enrolled (ECTS) students and 11 were external (M)OOC participants. Below, follows a presentation of the analysis of the interviews within each of the five levels of participation primarily members, observers and visitor, because they represent the group of participants who do not complete the course. The analysis provides the answer to the second research question concerning activities, needs and learning outcomes of the invisible learners.

\section{Student (enrolled)}

The students wrote most of the blog posts and also most of the comments on the blog. In other words, the enrolled students were accountable for most of the production and discussion in the course. The students took part in all course activities; reading course literature, producing, collaborating, writing blog posts, participating in online feedback sessions, commenting on blog posts. 


\section{Attendees}

Some of the participants in this group would be the so-called 'completing' in the sense that they did all course activities and completed the course. However, some attendees did only attend in part of the course. Thus, their participation is much similar to that of the enrolled students. From the interviews, it is learned that they see their role as "attending a course". The point of attending is that these participants more or less perceive themselves as students in a course. Thus, it is not surprising, that they all - like most of the other participants - entered the course with the ambition of completing it.

Some of the interviewed participants argued that they felt that they had to try out the ideas in their own practice to achieve any profound learning. Others argued that with all the time invested in the course they felt compelled to keep up the engagement to qualify for the final certificate. This group of participants is very similar to the 'completing' group of Kizilcec, Piech, and Schneider (2013), but they slightly differ, as the participant cannot be categorised as attendees throughout the whole course. At times participants will for instance go from attendee to member, and thus the same participant can belong to more than one category.

\section{Members}

Participants in this group can be said to be part of the course - but without attending it or aiming at completing it. These participants have not participated in all course activities; that is, they have typically not done the assignments, not participated in group work, and not written blog posts. They may occasionally participate in discussions.

In the interviews, the participants express a certain sense of belonging to the course activities. They are members in the sense that they can follow the activities, and it is legitimate to stay on the sideline and only take part in some of the activities. It is obvious that these students participated in other ways than the attendees and they had other approaches and objectives of participating. For example, several members had a strong focus on interacting and connecting with other people who share their interest in the field.

"To connect with people whom I share an interest with."

"That thing about engaging in and developing your network and connecting with other people."

"There is an opportunity to get in contact with many, many people in the whole country and learn about how they do things."

"I thought that I could be together with someone who speaks within the same discipline as me and who shares my interests."

"To be able to find like-minded."

This approach to the course meant that these students participated differently compared to the attendees. For example, the student below participated in discussions and also engaged in discussions with one of the student groups.

"I participated on the blog, where I commented on everything that I possible could." 
"Someone wanted to write about [a learning management system], and then I volunteered to comment on their work. ... So they used me by sending me some of their assignments, before they handed them in. ... They had some thoughts, and then I asked them questions in return, which they could reflect on."

\section{Observers}

Participants within this group have not contributed to group work, they have not worked on the assignments, and they have not written blog posts or commented on them. Within this group, some of the participants have to a large extent read the course literature, watched teacher videos and read the blog posts. Further, their evaluation of their own learning outcomes of reading course literature, watching teacher videos, reading blog posts, and reading blog discussions is high. Whereas the attendees have been somewhat stable and consistent in their participation in most course activities, the observers are very selective. Some have primarily read the course literature, whereas others have primarily spent time on reading the blogs and blog discussions. Thus, these participants express a wish to be part of the course on the sideline and choose what is relevant for them, as the following quotes show:

"I have used it for inspiration and new knowledge, and I think that it is nice to be able just to be present without having to be actively engaged. ... I have learned valuable things on the sideline."

"You knew that you could always go in and take a look at things and read, and new things would appear."

"It has been an educational course where is was OK to be a wallflower, because that is what I have been. And I have received valuable learning from the sideline."

"I would like to participate again another time, but I think that my starting point would be to participate on the sideline, only viewing. Next time that I will participate ... I will just do it in my spare time, and then just watch what you are doing."

The aim of these participants was to view and observe. As the quote below indicates, they were not interested in doing assignments or tasks, and they did not wish to collaborate or even discuss with other participants. But their "passive" observations were meaningful to them.

"I did it [took the course] to connect with the activities and see what happened and acquire knowledge about these things. Maybe to get updated, when I knew that I would not do the assignments."

\section{Visitors}

A final group is very similar to the observers. From data from Google Analytics, we could see that the course was used by non-registered participants. These are the ones that termed visitors. In the study, it was not doable to study these participants in details because it was only possible to see traces of them in Google Analytics. These data indicate that the visitors are even more selective than the observers, and that they only visit few elements in the course.

\section{New educational formats for professional development?}


Taken together, the members, observers and visitors are only rarely visibly active in the course. It was only possible to identify traces of their activities. However, they are active in the sense that they read literature, view videos, and they reflect on the course content in relation to their own practices. Therefore, it is not possible to say that they are attending a course, because they do not perform the course activities; that is handing in assignments and discussing with peers. Rather, they are using course activities as input to their current practices. From the outside or from the perspective of the teacher, they can be considered as consumers of course content. The members, observers and visitors will often be considered as dropouts or non-completing, and they would not count as successful participants. Further, MOOCs are primarily designed for active participation and with the aim of student completion. Such courses are designed in ways that imply student participation; doing assignments and participating in discussions. In other words, they are designed for students and attendees, not for members, observers and visitors. If it is educationally valuable - as the interviews indicate - to participate in MOOCs in different ways, the question is, how can educational formats for members, observers and visitors be designed. In this final section follows a discussion of the third research question by presenting three ideas for educational formats that aim at accommodating invisible learners in professional development.

Dron and Anderson $(2007 ; 2014)$ have proposed a model for social forms for learning in online contexts. The model contains three different social formations called group, net and set, that "all are bound by common attributes of sharing and communication that can contribute to the learning of others" (Dron \& Anderson, 2014, p. 72). The group is the most commonly used social form of our traditional formal educational activities. Also known as the class, a group is a unit of individuals gathered around a common (educational) purpose. The net is an aggregation of nodes, that being individuals or groups of individuals, or even things, that connect through interaction, one node at a time. Finally, the set which is the social form of an aggregation of people and things with common attributes. The model's usefulness lies in its ability to make sense of different social online educational settings both in formal and informal contexts. Below, the discussion of educational formats connects to these social formations.

\section{Open online course}

To accommodate the attendees of the MOOC, a traditional course format is suitable. An open online course is a formal educational procedure. The term 'course' implies an educational context and involves a lot of different qualities or concepts that distinguish it from other ways in which people might organise themselves. These characteristics align with the social form 'group' (Dron \& Anderson, 2014). This is of course not surprising, being that the 'core' of the course was designed for enrolled university students. What is interesting is that only a few of the participants from the outside engaged in the MOOC in this social form, in spite of invitations to do so. What we saw from the interviews is that the members and observers did not have a need for specific learning objectives and a specific course content. Rather, they were looking for inspiration and input. This suggests that the course might not have been the right format for them and their specific needs for professional development.

\section{Open online community}

The term 'open online community' is applied to describe an informal formation, being a network or a group of people organised around a certain context. A community might contain some of the characteristics that can accommodate the members, observers and visitors. A community might revolve around a certain practice, a certain activity, a certain content, a certain shared space or identity. The term 'community' signifies something else than the term 'course'. A community might 
be regarded as an aggregation of nodes in a network, and a network is not organised around a hierarchic structure (Dron \& Anderson, 2014). There are no authorities in a network just the ability to connect or to disconnect. A community is dynamic and constantly changing, nodes might connect, disconnect and even reconnect as they see fit. As opposed to a course, the existence of a community organised as a network is largely dependent of its members. Basically the community is its members and it would cease to exist if all the members disconnected from each other for one reason or another. This description of the community aligns very well with the social form net. Some of the participants did connect due to their mutual engagement in the MOOC, and it was also registered interactions and thus potential network related connections between the enrolled students and the participants from outside of the university.

\section{Networked learning around a common centre}

As stated earlier, only few outside participants did actually engage in the group or the network settings in the MOOC, albeit a bit more were part of the net than part of the group. The majority of the outside participants were not part of either social form. Sometimes the online learning activities end up in emerging social structures that can be described neither as groups nor as network connections.

On one hand, they do not belong to any group, they are on their own schedule and the purposes of the activities are set by themselves. On the other hand, they do not know anybody close enough to describe their engagement as a network. This is the social form of the set. The set consists of people and things with similar attributes and in the same categories (Dron \& Anderson, 2014). The important part here is that the set emerges as the MOOC progresses, it is not there from the start. The set takes shape from the participants and their blog posts, teacher videos and other content that is produced by the enrolled students in the group. It is the content generated primarily by the participants in the group, but also to some extent by the participants in the net, that makes it meaningful for the observers and to some extent the visitors to follow or return to the MOOC for inspiration and input that they use in their own practices with colleagues and other peers. Basically, the evidence points towards the notion that the set was the reason that the invisible learners actually participated.

\section{Conclusion}

The presented study provides insights into, how invisible learners engage in and make use of MOOCs. The analysis of the empirical data identified groups of members, observers and visitors as examples of invisible learners that engage in MOOCs in very different ways than enrolled students. The study shows that invisible learners looking for professional development are not necessarily interested in a traditional course structure with assignments, curriculum and learning objectives. In that sense, invisible learners are not necessarily interested in completing or even participating in (part of) a course. The results of the presented study point towards that networked learning should not dismiss other social forms that might support networked activities. Especially within professional development it can make sense to connect more traditional course or community activities to other learners by opening up these activities and allowing for both members, observers and visitors to connect and bring it out and into their own professional practices.

The findings from the study put forward questions concerning educational formats for invisible learners looking for professional development; learners for whom a course might not be the right format. The results of the presented study do not provide answers to these questions. However, the results do show that activities and products of groups or communities can be a focal point for networked learning activities of invisible learners in professional development. In the study, the observers and visitors used activities in the MOOC as part of or as an extension of their own 
networks. There are similarities with the studied MOOC and the original cMOOC 'Connectivism and Connective Knowledge' developed by Siemens and Downes in 2008 (Downes, 2013; Siemens, 2005). However, the current study points towards the distinction between different target groups and different roles that participants can and wish to play in an open online course. The study calls for more attention towards these different forms of learner engagement in design of future educational formats for professional development.

\section{References}

Clow, D. (2013, April). MOOCs and the funnel of participation. In Proceedings of the Third International Conference on Learning Analytics and Knowledge (pp. 185-189). Leuven, Belgium ACM.

Daniel, J. (2012). Making sense of MOOCs: Musings in a maze of myth, paradox and possibility. Journal of Interactive Media in Education, 2012(3), Art-18.

Dalsgaard, C., \& Thestrup, K. (2015). Dimensions of openness: Beyond the course as an open format in online education. The International Review of Research in Open and Distributed Learning, 16(6).

Downes, S. (2013). The quality of massive open online courses. In B. H. Kahn \& M. Ally (Eds.), International Handbook of E-learning (Vol. 1, pp. 65-77). New York: Routledge.

Dron, J. \& Anderson, T. (2007). Collectives, networks and groups in social software for e-learning. In T. Bastiaens \& S. Carliner (Eds.), Proceedings of E-Learn 2007--World Conference on E-Learning in Corporate, Government, Healthcare, and Higher Education (pp. 2460-2467). Quebec City, Canada: Association for the Advancement of Computing in Education (AACE). Retrieved September 20, 2018, from https://www.learntechlib.org/primary/p/26726/.

Dron, J., \& Anderson, T. (2014). Teaching crowds: Learning and social media. Athabasca University Press.

Ho, A. D., Chuang, I., Reich, J., Coleman, C., Whitehill, J., Northcutt, C., Williams, J. J., Hansen, J., Lopez, G., \& Petersen, R. (2015). HarvardX and MITx: Two years of open online courses fall 2012summer 2014 (HarvardX Working Paper No. 10). Retrieved September 20, 2018 from https://ssrn.com/abstract $=2586847$

Jordan, K. (2014). Initial trends in enrolment and completion of massive open online courses. The International Review of Research in Open and Distributed Learning, 15(1).

Kizilcec, R. F., Piech, C., \& Schneider, E. (2013). Deconstructing disengagement: Analyzing learner subpopulations in massive open online courses. In Proceedings of the Third International Conference on Learning Analytics and Knowledge (pp. 170-179). Leuven, Belgium ACM.

Littlejohn, A., \& Hood, N. (2018). Reconceptualising Learning in the Digital Age: The [un] democratising potential of MOOCs. Singapore: Springer.

Littlejohn, A., Hood, N., Milligan, C., \& Mustain, P. (2016). Learning in MOOCs: Motivations and self-regulated learning in MOOCs. The Internet and Higher Education, 29, 40-48. 
Milligan, C., \& Littlejohn, A. (2017). Why study on a MOOC? The motives of students and professionals. The International Review of Research in Open and Distributed Learning, 18(2).

Milligan, C., Littlejohn, A., \& Margaryan, A. (2013). Patterns of engagement in connectivist MOOCs. MERLOT Journal of Online Learning and Teaching, 9(2).

Pomerantz, J., \& Peek, R. (2016) Fifty shades of open. First Monday, 21(5).

Siemens, G. (2005). Connectivism: A learning theory for the digital age. International Journal of Instructional Technology and Distance Learning, 2(1).

Tashakkori, A., \& Teddlie, C. (Eds.). (2010). SAGE handbook of mixed methods in social \& behavioral research. Thousand Oaks, CA: SAGE. 